\title{
GANGRENE OF THE TOES IN SYPHILIS. DESCRIPTION OF A CASE WITH A CRITICAL REVIEW OF THE LITERATURE
}

\author{
BY \\ E. J. MOYNAHAN \\ Dermatological Registrar, Guy's Hospital; late Specialist in Venereolpgy, Royal Air Force
}

Stokes and others (1944) state that syphilis of the arteries of the extremities is comparatively uncommon, and that syphilitic thrombosis and endarteritic changes in the arterioles are rarer still. In the current standard work on peripheral vascular diseases (Allen, Baker, and Hines, 1946) there is merely passing reference to syphilis of the peripheral vascular tree ; the literature on peripheral vascular syphilis reviewed in the present paper is scanty, and the evidence presented does not always support the authors' claims to have established a diagnosis of syphilitic arterial disease. Further, there is a conflict of opinion between some pathologists, notably Warthin (1922) and Saphir (1929), and the majority of clinicians as to the relative incidence of syphilitic lesions in the peripheral vascular system ; some deny that such lesions occur. In view of this it is considered that the occurrence of gangrene of the toes in a syphilitic patient is worthy of record.

\section{Historical Survey}

The history of arterial syphilis may be said to begin with Vesalius (1514-64), who was the first to recognize an aneurysm of the thoracic and abdominal aorta in a living patient. The diagnosis was confirmed two years later at autopsy but he failed to associate it with syphilis. Ambroise Paré was the first to suggest syphilis as a cause of aneurysm (Garrison, 1929), and Jean Fernel also suspected the relationship between the two conditions. In his classic Latin poem "Syphilis sive Morbus Gallicus," Fracastoro (1483-1553) does not mention the effects of syphilis on the peripheral vessels, unless one construes

“... membris exangibus, atque lacertus

Inde graves dabat articulus extenta dolores."

(lines 345-346 in Wynne-Finch's edition) as indicating the clinical picture of gangrene of the limbs : but the context does not allow this.

In general the physicians of the sixteenth and seventeenth centuries did not suspect the connexion between syphilis and arterial disease, but paid more attention to its cutaneous, mucosal, and osseous manifestations. There were two notable exceptions. Lancisi (1654-1720) noted the frequent occurrence of aneurysms, and in his work "De motu cordis et aneurysmatibus," published in Rome in 1728, after his death, he discussed " aneurysma gallicum," thus clearly recognizing the role of syphilis in the production of aneurysms. Morgagni (1682-1771) gave a clear description of the macroscopic changes produced by syphilis in the aorta and the great vessels and had no doubts as to their origin.

Nevertheless, in spite of Morgagni's eminence as a morbid anatomist, the relationship between syphilis and cardiovascular disease continued to be ignored until nearly a century after his death. John Hunter helped to perpetuate this ignorance by stating in his book on aneurysms that he had never seen the brain, the heart, or the great vessels involved in syphilis. Such was the weight of Hunter's authority that it was not until the middle of the last century that his views were shown to be erroneous. In 1849 Dittrich published his memoir in which he described the changes he found in the carotid and sylvian arteries in a syphilitic patient; he correctly attributed the changes to syphilis. Soon afterwards, Sir Samuel Wilks (1863), the distinguished Guy's physician, showed that arteritis. played the major role in the cerebral accidents. which may occur in syphilis.

Twelve years later, in $1875, \mathrm{~F}$. H. Welch, in a paper entitled "On aortic aneurysm in the Army and the conditions associated with it," definitely established the relationship between aneurysmal dilatation of the aorta and syphilis. Welch was. then assistant Professor of Pathology at the Army Medical School, Netley, but his fundamental contribution remained unrecognized. It was not until the work of Doehle, twenty years later, that the profession as a whole accepted the ætiological role of syphilis in the production of aortic aneurysm. 
That syphilis might produce peripheral vascular disease was not suspected until late in the nineteenth century. The clinical and pathological knowledge existing then, however, was not complete enough to avoid confusion between syphilitic and nonsyphilitic affections of the limbs. As a result, syphilis was held responsible by some authors (Darier, 1904), for conditions which would not now be considered syphilitic. The discovery by Schaudinn and Hoffmann in 1905 of the Spirochata pallida as the causal organism of syphilis paved the way for Warthin's work on syphilitic disease of the peripheral vessels. His work did not appear until after the world war 1914-18, and, although it is not fully accepted by many clinicians, it may be regarded as the first scientific contribution to our knowledge of the pathology of syphilis as it affects the arteries, other than the aorta, its main branches, and the cerebral arteries. The present century has seen a great increase in our clinical understanding of peripheral vascular disease, and also the development of accurate methods for their investigation. Consequently, precise diagnosis has become possible in the majority of cases showing symptoms of peripheral vascular disorder. Nevertheless, syphilis is an exception, and the clinical diagnosis of peripheral vascular syphilis can usually be arrived at only by exclusion.

\section{Review of the Modern Literature}

Doehle (1895) was the first to recognize and describe the histopathology of syphilitic aortitis. He stated that the condition began with a round-cell proliferation in and around the vasa vasorum of the adventitia of the aorta, extending later to the media with consequent damage to the elastic tissue of the wall and eventual aneurysm formation.

Warthin (1922) held that syphilis affected the peripheral arteries in a similar way. He claimed to have demonstrated the presence of $S$. pallida in the iliac, femoral, popliteal, and tibial arteries in cases of perforating ulcer, gangrene, symmetrical gangrene simulating Raynaud's disease, and scler-osing atrophy. Warthin considered that the lesions which he found in those medium-sized vessels were essentially those of a mesarteritis. He thought that the changes in the smaller arteries presented the appearances of a panarteritis, periarteritis, or proliferating arteritis. The lesions were seldom of any size and could be detected only by microscopic examination. It is not surprising that the existence of these lesions, if in fact they do occur, had escaped notice, since the smaller vessels are rarely looked at, and still less frequently subjected to histological examination at autopsy.
Letulle and others (1925) described a case of intermittent claudication in a syphilitic patient with lesions of the aorta, iliac arteries, and vessels of the legs. They considered that the lesions found in the tibial arteries were those of a syphilitic arteritis similar to that found in lues of the cerebral arteries.

Saphir (1929), in a study of fifty cases of syphilitic aortitis, examined at autopsy the innominate, common carotid, superior and inferior mesenteric, and common iliac and femoral arteries for evidence of syphilitic disease. He considered that an endarteritis obliterans of the vasa vasorum of the adventitia of the aorta, accompanied by perivascular infiltration with lymphocytes, is the earliest manifestation of syphilis in the aorta. He adopted these criteria for evidence of early syphilis in the vessels. $\mathrm{He}$ interpreted interruption of the elastic lamellæ of the media by round-cell infiltration or connective tissue as a later manifestation of the syphilitic process. Changes which he considered to be characteristic of syphilis were found more frequently in the vasa vasorum of the larger vessels with a relatively rich tunica elastica than in the smaller vessels with their relatively rich musculature. By these standards he found evidence of syphilis :

in 33 out of 50 innominate arteries examined

in 29 out of 50 carotid arteries examined

in 15 out of 29 subclavian arteries examined

in 10 out of 50 common iliac arteries examined

in 10 out of 50 superior mesenteric arteries examined

in 3 out of 50 inferior mesenteric arteries examined

in 7 out of 50 femoral arteries examined.

Lian and others (1931) considered the role of syphilis to be under-estimated in arterial disease. In a discussion of arteritis obliterans of the lower limbs, they state that most cases of gangrene in the aged are due to a simple atheromatous change in the vessels, but that stenosing changes at a younger age should make the clinician think of syphilis.

Herrmann (1933) states that we are unable to say how often syphilis affects the peripheral arteries or to say with certainty if it does so at all. He recognized three clinical types which he called respectively the angiospastic, the endarteritic, and the thrombophlebitic. The angiospastic type affects the upper limb, and manifests itself as a chronic arteriospasm with constant pain in the distal part of the affected arm. Hermann thought that the vasospasm arose reflexly from chronic irritation of the perivascular nerve plexuses involved in the syphilitic process. The endarteritic type presents clinically as intermittent claudication, and this he attributed to an obliterative endarteritis of the terminal and smaller 
arterioles. The thromboarteritic type exhibits itself by extensive occlusion of all the major arterial pathways without gross gangrene.

Derrick and Hass (1935) described a case of diffuse arteritis which they considered to be of syphilitic origin. The patient was a young man in whom arteritic changes were found in the small vessels of the gut, liver, pancreas, kidneys; and adrenals, with occlusion of the vessels either by marked thickening of their walls, formation of thrombi, or a combination of both processes. There were numerous infarcts in the affected organs. No lesions were found in the voluntary muscles or in the skin. Spirochætes were found only in some areas of necrosis and inflammation in the duodenal mucosa. Before he died the patient had received arsenotherapy and serological tests had become negative. The clinical picture they describe resembles that of polyarteritis nodosa, and apart from the isolated finding of spirochætes in the duodenal mucosa there is little to suggest that syphilis was the cause of the extensive arterial disease found in this patient. They were emphatic that the spirochætes which they found were morphologically indistinguishable from those of syphilis, but the serological tests were negative. If syphilis had been responsible for the arterial changes one would have expected to find the spirochæte in many of the vessels and the serological tests should have remained positive. It must be concluded, therefore, that the authors are in error and that the probable diagnosis in this case was polyarteritis nodosa.

Grauer and Myers (1944) described a case of peripheral vascular syphilis involving the vessels of the legs in a white soldier of the U.S. Army. This man developed a small painful ulcer on the plantar surface of his fourth right toe, which was eventually amputated. Further lesions developed on his right foot after the toe had been amputated, and it was only then that a serological test (Wassermann) was done. This was found to be positive. The pulse of the dorsalis pedis artery could not be felt on either side. The anterior tibial pulses on both sides were also absent. A course of mapharsen and bismuth was given, with an excellent therapeutic response. The authors conclude that syphilitic peripheral vascular disease presents little that is distinctive clinically, and that the diagnosis can be arrived at only by a process of exclusion. A study of the literature as well as personal experience makes one endorse this view, which sums up the present status very well.

Learmonth. (1944), in a review of peripheral vascular disorders, mentions syphilitic arteritis as one of the conditions which may produce ischæmia of a limb or part of a limb. Leriche and Bertrand
(1946) state that in an experience extending over many years they never saw peripheral vascular disease due to syphilis.

\section{Case Report}

An aircraft hand, aged 31 years, was transferred to a Royal Air Force Special Treatment Centre on Aug. 15, 1943 , with the following history. Whilst he was undergoing his recruit's training course he complained of a painful ingrowing toe-nail on his right great toe. He was seen by a surgeon and was shortly afterwards admitted to an E.M.S. Hospital, where the toe-nail was removed. A few days after the operation he complained of pain in the toe, which was found to be gangrenous and the terminal phalynx was removed. Within forty-eight hours of this, the fifth toe of the same foot became gangrenous and had to be removed. Serological tests were then done, and both the Wassermann and Kahn tests were positive. Before his transfer to the Special Treatment Centre anti-syphilitic treatment with neoarsphenamine and bismuth was begun.

On Admission.-Physical examination revealed a moderately well-nourished man, who looked pale, ill, and older than his years. Intelligence was below average ; he was unco-operative, of a surly disposition, and answered questions reluctantly, but he was well orientated. He proved to be a difficult disciplinary problem, and he absented himself without leave and refused to submit to most of the investigations which would have amplified this case report.

Mouth.-Hygiene was poor, the teeth deficient and neglected, the mucosæ pale, the fauces clear. There was no glandular enlargement and no evidence of congenital lues.

Cardiovascular System.-The heart was normal in size, shape, and position, with no bruits. Blood pressure was $120 / 60 \mathrm{~mm}$. $\mathrm{Hg}$. The pulse was regular. Brachial, radial, and ulnar arteries were normal, and the pulses equal on both sides. There were no trophic changes in the hands. The femoral arteries of the legs and the popliteal arteries appeared normal, with pulses equal. the volume of the popliteal arteries was good. Neither dorsalis pedis artery could be felt and there was only faint pulsation in the posterior tibials.

Central Nervous System.-The pupils were equal and concentric. They were small, but reacted to light and on convergence. The fundi appeared normal but arteries looked rather narrow. There was left facial weakness and weakness of the right twelfth nerve. The superficial and deep reflexes were present and equal on both sides. The plantar response was flexor on both sides; there was no sensory loss or disturbance.

Other cystems appeared normal. The urine contained no sugar or albumin. The blood Wassermann and Kahn reactions were strongly positive. The cerebrospinal fluid was not examined as the patient refused lumbar puncture.

Feet.-The right fifth toe, and the terminal phalanx of the right great toe were missing, and the scar and wound were healing slowly. The foot was pale but there was 
no cyanosis and it was not cold. The left foot appeared normal.

\section{Discussion and Differential Diagnosis}

In the case described above there can be little doubt concerning the cause of the neurological findings. They are not uncommon in cerebrovascular syphilis. It is more difficult to establish that the gangrene of the toes was due to syphilis, and in order to do so it is necessary to consider the other causes of gangrene. The following conditions were considered, as-they must be in every case of gangrene arising in a syphilitic patient, before the conclusion was reached that syphilis was responsible for the loss of this patient's toes.

Diabetic Gangrene.-This could be excluded by the normal urinary findings. In doubtful cases a sugar tolerance curve may be required, but it was not necessary here.

Raynaud's Disease.-This was ruled out by the history. Furthermore, this malady is much commoner in women, and in practically every case the upper limbs are involved. The peripheral arterial pulses are always present in Raynaud's disease, but were not felt in this patient. There is usually bilateral and symmetrical involvement of the limbs, and gangrene, if present, is nearly always slight. Raynaud's disease never presents with gangrene of the toes as a first symptom.

Arteriosclerotic Gangrene.-This usually occurs in males over 50. Calcified arteries are frequently present, and can be felt or demonstrated by radiography. There was no clinical evidence of arteriosclerosis in this case.

Thrombo-angiitis Obliterans (Buerger's Disease).This is not uncommonly the cause of gangrene of the toes in patients of his age and sex. Further, our patient had asymmetrical gangrene involving the lower limb with absent peripheral pulses, a picture which would fit in well with a diagnosis of Buerger's disease. However, there was no history of intermittent claudication or other symptoms of peripheral impairment. The patient was an Irishman, a race in which few cases of the malady have been reported.

Periarteritis Nodosa.-This may cause gangrene of the toes or part of a limb. It may also give rise to neurological signs. Usually the whole clinical picture is bizarre, with fever, weakness, loss of weight, albuminuria, hypertension, and eosinophilia as the commonest findings. There is no constant clinical picture, and the diagnosis is often made only at autopsy. The disease usually affects many arteries, so that it can mimic a large number of maladies. It is becoming evident, too, that the disease may be confined to a few vessels, so that, in the case under consideration, both the neurological signs and the gangrene could have been attributed to periarteritis nodosa. This diagnosis was thought to be unlikely in view of the otherwise negative findings and the fact that a diagnosis of syphilis accounted more satisfactorily for the neurological signs. The good response to anti-syphilitc treatment was also considered to weigh against this diagnosis, but it should be borne in mind that long remissions have been reported in some undoubted cases of periarteritis nodosa.

Acute Arterial Embolism.-By failure to find any of the common conditions in which this might arise, acute arterial embolism was dismissed as a cause of gangrene in this patient. In particular; there was no evidence of auricular fibrillation, myocardial infarct, or bacterial endocarditis;- neither was there any sign of aneurysm affecting the wall of any vessel in the limb showing gangrene.

Arterial Thrombosis.-Arterial thrombosis was considered but rejected as the cause of the peripheral vascular changes. None of the predisposing causes was present. These include acute infections, blood diseases - particularly leukemia and polycythæmiathrombo-angiitis obliterans, periarteritis nodosa, disseminated lupus erythematosus, and sclerodermia.

Traumatic Gangrene.-Traumatic gangrene such as follows injury to the main vessel of a limb could obviously be excluded in the absence of any such injury. The trauma of the operation, however, may well have determined the onset of gangrene in this patient; and it is probable that without this added burden to the impaired circulation in his toes, necrosis would not have occurred. The postoperative inflammatory response proved too much for the diseased vessels and led to thrombosis, with consequent ischæmia, of the terminal digital arteries.

Toxic Gangrene.-Gangrene resulting from ergotism or arsenical poisoning could obviously be excluded in the absence of any history of his taking these substances. Chemical gangrene, such as might follow the application of a dressing containing phenol, could also be excluded.

Cryopathic Gangrene.-Gangrene due to frostbite or other effects of cold obviously did not need to be considered:

Syphilis is the only cause left, after excluding the foregoing, to account for the occurrence of gangrene in this patient. This is the only conclusion that can be drawn from the history, clinical signs, and serological findings. It may be assumed that the removal of his ingrowing toe-nail merely coincided with a phase in his syphilitic infection when there was a widespread involvement of his arteries. The 
- trauma of the operation, occurring at this phase of his disease, may therefore be regarded as the precipitating factor. It is reasonable to presume that, had he not been operated on at that particular time, gangrene would not have ensued although he would have developed the neurological manifestations of syphilis which did in fact show.

It is unfortunate that, owing to his refusal to submit to further investigation and also to lack of facilities for a more thorough study of his peripheral vessels, unequivocal proof of the syphilitic origin of his gangrene could not be obtained. In particular, the following investigations omitted in the study of this case might have produced conclusive proof of the syphilitic nature of the changes in the arteries of his foot: (a) histological examination of the tissues removed at amputation, and $(b)$ biopsy of the tissues of the foot. The sections obtained should be stained for spirochætes, because it is necessary to demonstrate their presence before one can be certain that the changes seen are in fact due to syphilis. This must be regarded as of crucial importance in any study of syphilitic disease of the peripheral vessels, because the histological changes in themselves are not specific.

\section{Conclusion}

The study of the literature and experience in the clinic show that gangrene of a digit due to syphilis is an extremely ráre event. There are no pathognomic signs in peripheral vascular syphilis, but certain criteria should be fulfilled before a diagnosis of peripheral vascular syphilis is made. These are : (1) positive serological tests, repeated more than once; (2) signs of clinical activity elsewhere ; (3) the patient should be under 50 and should show no signs of arteriosclerosis ; (4) the diastolic pressure should not exceed $90 \mathrm{~mm}$. $\mathrm{Hg}$., thus excluding all hypertensive cases and many of polyarteritis nodosa ; (5) the blood picture should be within the normal range ; (6) the patient should have had no heavy metal, arsenic, or sulphonamide therapy prior to the onset of symptoms, since some cases of polyarteritis have been attributed to drug allergy ; (7) the urine should not contain sugar; $(8)$ there should be a satisfactory response to appropriate anti-syphilitic therapy.

The diagnosis can be confirmed in one way only, that is, the demonstration of spirochætes in the affected vessels. This has rarely been accomplished, so that in most cases the diagnosis of peripheral vascular syphilis is one that can be arrived at only by excluding the other causes of arterial disease.

\section{REFERENCES}

Allen, E. V., Barker, N. W., and Hines, E. A. (1946). "Peripheral Vascular Disease." W. B. Saunders. Philadelphia and London.

Darier, J. (1904). " De l'Artérite Syphilitique." Rulff. Paris.

Derick, C. L., and Hass, G. M. (1935). Amer. J. Path., 11, 291.

Doehle, K. G. (1895). Dtsch. Arch. klin. Med., 55, 190

Erichsen, J. E. (1844). " Observations on Aneurysm." Sydenham Society. London.

Fracastoro, G. "Syphilis, or the French Disease." Trans, by Wynne-Finch, H. (1935). Heineman. London.

Garrison, F. H. (1929). " Introduction to the Historyo of Medicine." Fourth Edition. W. B. SaundersPhiladelphia and London.

Grauer, F. H., and Myers, H. L. (1944). Amer. J. Syph. 28, 458.

Herrmann, L. G. (1933). Ibid., 17, 305.

Learmonth, J. R. (1944). Brit. med. Bull., 2, 136.

Leriche, R., and Bertrand, I. (1946). "Thromboses Artérielles." Masson et Cie. Paris.

Letulle, M., Heitz, J., and Magniel, M. (1925). Arch. Mal. Cour, 18, 497.

Lian, C., Blondel, A., Barrieu, R., and Ribas Soberano, F. (1931). Paris méd., 2, 21.

Saphir, O. (1929). Amer. J. Path., 5, 397.

Stokes, J. H., Beerman, H., and Ingraham, N. R. (1944). "Modern Clinical Syphilology." W. B. Saunders, Philadelphia and London.

Warthin, A. S. (1922). N.Y. med. J., 115, 69.

Welch, F. H. (1875). Med. Chir. Trans., Lond., 41, 59.

Wilks, S. (1863). Guy's Hosp. Rep., 9, (ser. 3), 1. 